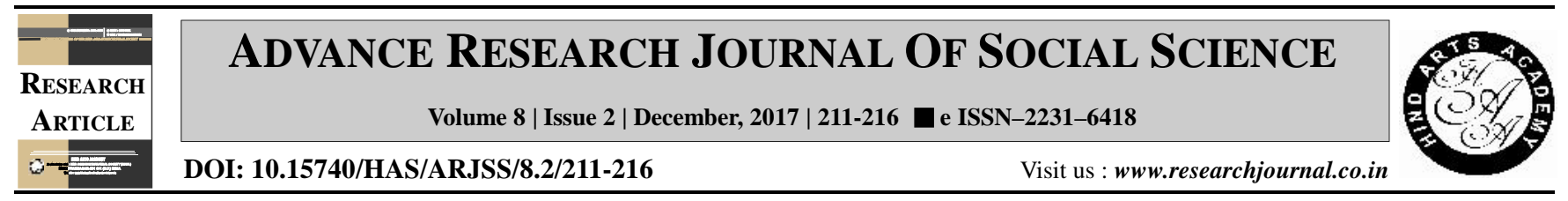

\title{
Knowledge of mothers regarding the causes of unintentional injuries among 4-6 year children in Udaipur city, Rajasthan
}

Preeti Verma* and Garima Babel ${ }^{1}$

Govt. Meera Girls College, UDAIPUR (RAJASTHAN) INDIA

'Bhupal Nobles' University, UDAIPUR (RAJASTHAN) INDIA

(Email: darshan.verma9@gmail.com; mayankgarima@gmail.com)

\section{ARTICLE INFO :}

$\begin{array}{lll}\text { Received } & : & 21.06 .2017 \\ \text { Revised } & : & 05.10 .2017 \\ \text { Accepted } & : & 20.10 .2017\end{array}$

\section{KEY WORDS :}

Unintentional injuries, Knowledge, Communication strategies

HOW TO CITE THIS ARTICLE : Verma, Preeti and Babel, Garima (2017). Knowledge of mothers regarding the causes of unintentional injuries among 46 year children in Udaipur city, Rajasthan. Adv. Res. J. Soc. Sci., 8 (2) : 211-216, DOI: 10.15740/HAS/ARJSS/8.2/211216.

*Author for correspondence

\section{ABSTRACT}

Unintentional injuries are the leading threat to child's continued existence but still, its prevention is not a serious apprehension especially in India. Consequently, the most hopeful one to battle injury problem is starting from the bottom and that could be achieved by addressing the mother's knowledge base. Accordingly, 180 mothers of Udaipur (Rajasthan) were selected through a stratified purposive sampling technique using a self designed questionnaire to elicit response regarding the causative factors of the most prevalent unintentional injuries i.e. Burns, Scalds and Electrocution, Poisoning and Drowning among children of 4-6 year age. The overall mean knowledge score of all the 180 mothers in the present research embrace that respondents don't clutch good knowledge regarding the causative factors of these three unintentional injuries. Also, the study exposed to a significant gap in mothers' overall knowledge towards Unintentional injury causes as the scores ranged from 80.66 to 111.31 of 180 maximum score. The findings make known that the overall mean knowledge score was highest in Poisoning (111.31) followed by Burns, Scalds and Electrocution (80.81) and Drowning (80.66). These set of findings facilitated in formulating innovative and targeted communication strategies so that, a few key steps can be taken forward by the mothers in the battle to trim down injuries from the blooming lives each day. 